\title{
Cost of care for patients on maintenance haemodialysis in public facilities in Cameroon
}

\author{
Marie Patrice Halle ${ }^{1,2}$, Natacha Nono Jimkap', François Folefack Kaze ${ }^{3}$, Hermine Fouda ${ }^{2,3}$, Eugene Priso Belley ${ }^{3,4}$, \\ Gloria Ashuntantang ${ }^{3}$ \\ 'Faculty of Medicine and Pharmaceutical Science, University of Douala, ${ }^{2}$ Department of Internal Medicine, Douala General Hospital, \\ ${ }^{3}$ Faculty of Medicine and Biomedical Sciences, University of Yaoundé, , '4 Department of Gynaecology, Douala General Hospital, Cameroon.
}

\section{ABSTRACT}

Background: The management of end-stage kidney disease constitutes a heavy burden on communities worldwide due to the high cost of renal replacement therapy (RRT). Data on the cost of RRT are scanty in low-income countries. This study aimed to evaluate the global cost of haemodialysis in Cameroon, an emerging economy in Central Africa. This will provide data to help healthcare planners develop more cost-effective strategies for the care of these patients.

Methods: A prospective cost analysis of chronic haemodialysis care in three public-sector facilities was conducted in Cameroon. Both incident and prevalent patients were enrolled and followed up for 6 months. Patient data and costs were collected from patient interviews, medical records, bills, hospital price-lists and the procurement departments of the hospitals. Direct medical costs included outpatient consultation fees, dialysis consumables, dialysis session fees, drugs, laboratory and radiological tests. Non-medical direct costs included the cost of transport, feeding, water and electricity. Indirect costs related to the monthly loss of productivity for patients and their caretakers. The annual costs were calculated as the median costs for 6 months multiplied by 2 and were expressed in the local currency, the Central African franc (XAF), and US dollars (\$).

Results: A total of 154 patients (62.3\% males), mean age of $46.8 \pm 15.2$ years, were included, with 6 I 30 dialysis sessions completed during the study period. The annual median cost of haemodialysis per patient was XAF 7988 800 (\$ |3 58 I). Out-of-pocket payments amounted to XAF 2420300 (\$ 4 | | 4), accounting for 30\% of the total cost. The median direct cost was XAF 7458200 (\$ 12 679) and indirect cost XAF 530600 (\$902). Direct medical costs accounted for $88 \%$, mainly due to dialysis consumables. In the initiation phase, additional costs of $\$ 754$ were incurred. The cost of hospitalization, laboratory and radiology tests, feeding, consultation fees and some drugs varied significantly among facilities.

Conclusions: Compared to the national gross domestic product per capita in Cameroon, the cost of care of patients on haemodialysis is high. Out-of-pocket payments are out of the reach of most patients and there is a need for implementing other cost-effective strategies to prevent and manage end-stage kidney disease in our setting.

Keywords: cost analysis, haemodialysis, peritoneal dialysis, Cameroon.

\section{INTRODUCTION}

The availability of renal replacement therapy (RRT) such as dialysis and transplantation for the treatment of endstage renal disease (ESRD) has been one of the great successes of medicine in past decades. It has been available in high-income countries for more than 50 years, with rapid growth in the number of people treated $[1,2]$.
The use of dialysis varies among regions, due to differences in population demographics, prevalence of ESRD, and especially access to and provision of RRT [3,4]. The management of renal failure is disproportionately costly in comparison with other medical conditions and constitutes a heavy burden on communities worldwide [5-7].

Received 04 August 2017; accepted 14 November 2017; published 04 December 2017 
RRT consumes many resources, the equipment and consumables are expensive and skilled personnel are required [8]. In contrast to high- and middle-income countries, data on the cost of RRT is sparse in low-income nations, especially in sub-Saharan Africa (SSA) [6,7,9]. In 2010, the annual cost for ESRD-related medical expenses in the USA was estimated at $\$ * 28$ billion [3] In the UK, the cost of treatment for ESRD was I-2\% of the budget of the National Health Service, for patients who constituted only $0.05 \%$ of the population [ 10$]$.

Globally, the number of patients receiving RRT in 2010 was estimated at 2.618 million, with only $7.2 \%$ living in lowermiddle income and low-income countries. Further modelling suggests that this number will more than double to 5.439 million by 2030, mostly in developing countries. African patients with ESRD have the lowest access to RRT, with only 9-16\% being treated; in central and eastern Africa the treatment rate is estimated to be as low as $1-3 \%$ [2].

In SSA, in-centre haemodialysis (HD) is the most common modality of RRT with its provision being very challenging. Treatment for all is beyond the reach of most countries due to the lack of funds or health insurance to cover the high costs for the ever-increasing number affected. Despite this high disease burden, renal registries are almost nonexistent and there is a lack of published data on the costs of dialysis in African countries [7, I I, 12].

Cameroon is a low-income country, with a population of 22.5 million. The human development indices are poor, with a low gross domestic product of $\$ 34$ billion in 2015 and only $5.1 \%$ of the country's budget being spent on health care [13]. The prevalence of chronic kidney disease (CKD) in Cameroon is estimated at 10-13.2\% [14,15]. Incentre haemodialysis started in the early 1980s and in the last decade much attention has been focused on the treatment ofESRD with the establishment of public haemodialysis centres nationwide [16]. About I 200 patients were on treatment in 9 public-sector treatment centres at the end of 2016 . Since 2002, dialysis sessions have been subsidized by the government in public-sector centres. Patients pay a fee of XAF 5000 (\$8.5) per dialysis session. This does not include related costs for vascular access, laboratory tests, medication, feeding, transportation, hospitalization and vaccination. All these additional costs are borne by patients and their families. This study aimed to evaluate the global cost of ESRD treated by HD in a resource-limited country, to help healthcare planners to develop strategies to mini-

\section{METHODS}

A prospective cost-analysis of $\mathrm{HD}$ care was conducted in 3 facilities in Cameroon (two tertiary, one regional). All centres are equipped with Fresenius $4008 \mathrm{~S}$ dialysis machines, use consumables produced by the manufacturers and do not practise dialyzer reuse. In these centres, as in other centres in Cameroon, patients undergo two dialysis sessions of 4 hours per week.

We included consenting incident and prevalent patients on HD for ESRD and followed them up for 6 months from November 2012 to April 2013. Outcomes of interest were expenditure by patient or their families as well as by the hospital in relation to HD care. Staff salaries and other utilities, furniture and cost of maintenance of the building were excluded from the analysis. Data and costs were obtained from patient interviews, medical records, bills, hospital price-lists and procurement departments of the hospitals. Direct costs analysed included direct medical costs (dialysis session fees, cost of consumables, drugs, outpatient consultation fees, laboratory and radiological tests) and direct non-medical costs (transport, feeding, water and electricity). One indirect cost considered was the monthly loss of productivity for patients and their caretakers estimated from the time spent for the treatment. Out-of-pocket payments (borne by patients and families) included dialysis session fees, vascular access, all drugs, laboratory and radiology tests, vaccinations, meals and transportation. All other costs were borne by the government/hospital.

The cost of incident patients was used to calculate the cost at the initiation phase. The cost of electricity and water was calculated with the assistance of an engineer at each hospital. Electricity consumption was calculated by taking into account all electrical appliances at each unit, consumption by each appliance, and the duration of its usage per month. Water consumption was calculated by multiplying hours of dialysis by the hourly water usage per dialysis machine, and the number of machines at each dialysis unit.

Data analysis used SAS/STAT ${ }^{\circledR} \vee 9.1$ for Windows (SAS Institute Inc., Cary, NC, USA). We reported results using counts and percentages, means and standard deviations (SD) or median (min-max). Comparisons across study centres were made using the chi-squared test and analysis of variance (ANOVA). Costs were expressed as the median of the expenditure recorded over 6 months per patient in the local currency) and converted to US dollars, based on the exchange rate at the end of the study ( I XAF $=\$ 0.0017)$. We estimated the annual cost by multiplying 
the median cost by 2 . A p-value $<0.05$ was considered statistically significant.

The study received administrative authorization from the Douala General Hospital and ethical approval was obtained from the ethical board of Douala University.

\section{RESULTS}

Of the 154 participants included, 106 (68.8\%) were prevalent and 48 (31.2\%) were incident patients. The mean age was $46.8 \pm 15.2$ years and 96 (62.3\%) were males, with no difference between centres. The majority of our patients were in a low socio-economic class with more than $25 \%$ without income. Only 9\% had medical insurance. The total number of dialysis sessions included was 6130 (mean 39.8 sessions per patient). See Table I.

The median cost of haemodialysis per patient for 6 months was XAF 3994400 (\$6 790), an annual cost of
XAF 7988800 (\$ |3 58I). Out-of-pocket payments per patient was XAF 2420300 (\$4 | | 4), accounting for 30.3\% of the total cost. Direct costs totalled XAF 7458200 (\$12 679) and indirect costs XAF 530600 (\$902). Direct medical costs accounted for $87.7 \%$ ( $\$$ | | 904) of the total costs, mainly due to the cost of dialysis consumables (59.8\%, \$ 8120). Direct non-medical costs accounted for $5.7 \%(\$ 775)$ and indirect costs for 6.6\% (\$902) of the total cost (Table 2).

In the initiation phase, additional costs of $\$ 775$ were incurred, mainly due to the cost of vascular access, drugs and hospitalization (Table 3).

The itemized costs at each hospital are shown in Table 4. The costs of hospitalization ( $p<0.013$ ), laboratory and radiology tests $(p<0.001)$, some drugs ( $p<0.005)$, consultation fees and feeding $(p<0.00 I)$ varied significantly among facilities.

Table I. Baseline characteristics of the study population at the different dialysis centres.

\begin{tabular}{|c|c|c|c|c|c|}
\hline & DGH & YGH & BRH & $\mathrm{P}$ & Total \\
\hline$N(\%)$ & $70(45.5)$ & $4 \mid(26.6)$ & $43(27.9)$ & & $154(100.0)$ \\
\hline Men (\%) & $42(60.0)$ & $29(70.7)$ & $25(58.1)$ & 0.42 & $96(62.3)$ \\
\hline Mean age, years (SD) & $46.6(15.16)$ & $46.04(14.80)$ & $47.76(15.76)$ & 0.88 & $46.77(15.15)$ \\
\hline \multicolumn{6}{|l|}{ Level of formal education, $n$ (\%) } \\
\hline None & । ( 1.4$)$ & $0(0.0)$ & $2(4.7)$ & & $3(1.9)$ \\
\hline Primary & $14(20.0)$ & $4(9.8)$ & II (25.6) & & $29(18.8)$ \\
\hline Secondary & $33(47.1)$ & $19(46.3)$ & $16(37.2)$ & & $68(44.2)$ \\
\hline University & $22(31.4)$ & $18(43.9)$ & $14(32.6)$ & 0.24 & $54(35.1)$ \\
\hline \multicolumn{6}{|l|}{ Place of residence, $\mathrm{n}(\%)$} \\
\hline Same town as dialysis centre & $67(95.7)$ & $37(90.2)$ & $26(60.5)$ & & I $30(84.4)$ \\
\hline Out of town & $3(4.3)$ & $4(9.8)$ & $17(39.5)$ & $<0.000$ I & $24(15.6)$ \\
\hline \multicolumn{6}{|l|}{ Monthly income (XFA), n (\%) } \\
\hline No income & $21(30.0)$ & $9(22.0)$ & $10(23.3)$ & & $40(26.0)$ \\
\hline$<22500$ & । ( 1.4$)$ & I (2.4) & $3(7.0)$ & & $5(3.2)$ \\
\hline $22500-50000$ & $13(18.6)$ & $7(17.1)$ & $6(14.0)$ & & $26(16.9)$ \\
\hline $50000-100000$ & $13(18.6)$ & $4(9.8)$ & $7(16.3)$ & & $24(15.6)$ \\
\hline $100000-200000$ & $13(18.6)$ & $8(19.5)$ & II (25.6) & & $32(20.8)$ \\
\hline $200000-300000$ & I ( 1.4$)$ & $6(14.6)$ & $4(9.3)$ & & $11(7.1)$ \\
\hline >300 000 & $8(11.4)$ & $6(14.6)$ & $2(4.7)$ & 0.21 & $16(10.4)$ \\
\hline Insurance, n (\%) & II (I5.7) & $2(4.9)$ & I (2.3) & 0.024 & $14(9.1)$ \\
\hline Number of dialysis machines & 16 & 12 & 7 & & 35 \\
\hline Number of dialysis sessions & 2855 & 1602 & 1673 & & 6130 \\
\hline
\end{tabular}




\begin{tabular}{|c|c|c|c|}
\hline & XAF & $\$$ & $\%$ \\
\hline Direct costs & 7458199 & 12679 & 93.4 \\
\hline Medical & 7002478 & 11905 & 87.7 \\
\hline Dialysis session fees" & $480000(120000-640000)$ & 816 & 6.0 \\
\hline Dialysis consumables" & 4776623 & 8120 & 59.8 \\
\hline Vascular access ${ }^{*}$ & $217500(60000-575800)$ & 370 & 2.7 \\
\hline Blood transfusions" & $216950(30000-697000)$ & 369 & 2.7 \\
\hline Drugs for hypertension" & $164260(13560-698614)$ & 279 & 2.1 \\
\hline Heparin* & 74100 (7 450-526 296) & 80 & 0.6 \\
\hline Other drugs* & $105215(200-621680)$ & 179 & 1.3 \\
\hline Erythropoietin* & $560000(20000-4272000)$ & 952 & 7.0 \\
\hline Iron" & $4 \mid 600(4900-480000)$ & 71 & 0.5 \\
\hline Laboratory and radiology tests" & 123930 (2 000-1 020 800) & 211 & 1.6 \\
\hline Hospitalization* & 247300 (20 000-6 80। 098) & 420 & 3.1 \\
\hline Consultation fees" & 14000 ( 1 200-84 000) & 24 & 0.2 \\
\hline Vaccinations" & 8000 (7 000-21 000) & 14 & 0.1 \\
\hline Non-medical & 455721 & 774 & 5.7 \\
\hline Transportation* & 122400 (3000-| 704000$)$ & 208 & 1.5 \\
\hline Meals* & 72000 (4 800-352 800) & 122 & 0.9 \\
\hline Water* & 26062 & 44 & 0.3 \\
\hline Electricity & 235259 & 400 & 2.9 \\
\hline Indirect costs & 530562 & 902 & 6.6 \\
\hline Total out-of-pocket costs & 2420255 & 4114 & 30.3 \\
\hline Total state/hospital costs & 5037944 & 8565 & 63.1 \\
\hline Total costs & 7988761 & 13581 & 100.0 \\
\hline
\end{tabular}

\section{DISCUSSION}

The reported cost of dialysis varies considerably among regions and countries [7]. Our annual cost was approximately \$13 581, with out-of-pocket payments accounting for 30\%. This is close to that reported in Iran (\$ | I 549) [17] but is lower than in most developed countries and some low-income nations. The annual cost of haemodialysis has been estimated at $\$ 87500$ in the USA [18], between \$22 000-55 000 in Nigeria [19,20], \$ 46332 in Saudi Arabia [2 I], \$ 27440 in Tanzania [22] and \$ 28570 in Brazil [23]. One of the reasons for our lower cost is that we did not include the staff and building costs as has been done in other studies.

Lower costs have been reported in low/middle-income countries such as Indonesia (\$4900-6500) [24], South
Africa (\$7000) [16], Sri Lanka (\$5869-8804) [25], Sudan (\$6847) [26] and India (\$3000) [27]. These differences may be explained by many factors including the annual per capita income of countries, the methods used in estimating costs, different management protocols, and differences in local import duties, drugs, laboratory tests and the costs of consumables.

The main contributors to cost in our study were those related to the dialysis procedure and, in particular, the haemodialysis consumables. Similar results were reported in Sri Lanka [28] and in Brazil [23] whereas in Europe the haemodialysis procedure accounts for only $29-53 \%$ of the cost [29-3I]. Like most SSA countries, we import all dialysis supplies from Europe, so the cost of transportation, 


\begin{tabular}{|c|c|c|c|c|c|}
\hline & Initiation & & Maintenance & & $\mathrm{P}$ \\
\hline & $\mathrm{XAF}$ & $\$$ & $\mathrm{XAF}$ & $\$$ & \\
\hline Direct costs & 7678553 & 13054 & 7232433 & 12273 & \\
\hline Medical & 7220833 & 12277 & 6762313 & 11495 & \\
\hline Dialysis session fees" & $437500(120000-530000)$ & 744 & $490000(270000-640000)$ & 833 & $<0.00$ । \\
\hline Dialysis consumables* & 4776623 & 8120 & 4776623 & 8120 & $>0.999$ \\
\hline Vascular access" & $217500(60000-575800)$ & 370 & - & - & \\
\hline Blood transfusions" & $268000(73000-67 \mid 250)$ & 456 & $201250(30000-697000)$ & 342 & 0.005 \\
\hline Drugs for hypertension* & $185180(68 \mid 20-698614)$ & 315 & $137600(13560-593400)$ & 234 & 0.010 \\
\hline Heparin" & $89400(8100-526296)$ & 152 & 66300 (7450-263 580) & 113 & 0.028 \\
\hline Other drugs* & 133670 (24 400-597 240) & 227 & $92040(200-621680)$ & 156 & 0.001 \\
\hline Erythropoietin" & $460000(40000-4272000)$ & 782 & $580000(20000-1800000)$ & 986 & 0.387 \\
\hline Iron" & $56600(13800-480000)$ & 96 & $41000(4900-219600)$ & 70 & 0.181 \\
\hline Laboratory and radiology tests" & 195600 (4 000-I 624 |44) & 333 & 110200 (2000-650 600) & 187 & 0.001 \\
\hline Hospitalization* & 375960 (30 400-6 80। 098) & 639 & $247300(23000-3364566)$ & 420 & 0.112 \\
\hline Consultation fee* & $16800(1800-84000)$ & 29 & $12000(1$ 200-42 000) & 20 & $<0.00$ । \\
\hline Vaccinations" & $8000(8000-8000)$ & 14 & $8000(7000-21000)$ & 14 & $>0.999$ \\
\hline Non-medical & 457720 & 777 & 470120 & 778 & \\
\hline Transportation* & $122000(3000-834000)$ & 207 & 122400 (I5 200-1 704000$)$ & 208 & 0.612 \\
\hline Meals* & $74400(4800-212200)$ & 126 & $86400(5000-352800)$ & 126 & 0.122 \\
\hline Water" & 26062 & 44 & 26062 & 44 & $>0.999$ \\
\hline Electricity & 235258 & 400 & 235258 & 400 & $>0.999$ \\
\hline Indirect costs & $530 \mid 18$ & 901 & 532668 & 906 & \\
\hline Total out-of-pocket costs & 2640610 & 4489 & 2194490 & 3709 & \\
\hline Total state/hospital costs & 5037943 & 8565 & 5037943 & 8565 & \\
\hline Total costs & 8208671 & 13955 & $7765 \mathrm{IOI}$ & 13180 & \\
\hline
\end{tabular}

currency exchange and import duties all add to the cost of these items.

The cost of consultation fees, feeding, drugs, hospitalisation, laboratory and radiology tests varied among our facilities. These were higher in Douala, the economic capital of Cameroon, compared to Buea, a rural town. This probably reflects the stratification of healthcare costs according to the economic standards of towns within the country. Direct medical costs accounted for almost $90 \%$ of our costs and were dominated by the cost of dialysis consumables.

Dialysis is relatively more expensive for poorer than for richer developing countries and may not be cost-effective for low-income countries such as Cameroon [7, I I]. Compared to the national income, the costs of haemodialysis are prohibitive, and beyond the financial capacity of most governments. In Cameroon only $5.1 \%$ ( $\$ 1.3$ billion) of the budget is allocated to health care. With other burning health issues such as high maternal and infant mortality, HIVIAIDS and undernutrition, haemodialysis becomes a serious economic burden on the healthcare sector [13]. Despite the government subsidies, the out-of-pocket expenditure borne by patients and their families is almost one-third of the total cost. This is extremely high, especially in the initiation phase when there are the additional costs of vascular access, drugs and hospitalisation. This is out of the reach of most of our patients, who belong to the lower socio-economic class and often have no income. In our setting, health insurance is almost non-existent. Other studies have also shown that in countries in SSA, even 


\begin{tabular}{|c|c|c|c|c|}
\hline & $\begin{array}{c}\text { DGH } \\
(n=70)\end{array}$ & $\begin{array}{c}Y G H \\
(n=4 I)\end{array}$ & $\begin{array}{l}\text { BRH } \\
(n=43)\end{array}$ & $\mathrm{P}$ \\
\hline Dialysis session fee ${ }^{*}$ & $480000(160000-640000)$ & $495000($ (I20 000-560 000) & $480000(280000-530000)$ & 0.270 \\
\hline Dialysis consumables & 4894285 & 4688780 & 4668837 & \\
\hline Water & 26770 & 25675 & 25497 & \\
\hline Electricity & 285454 & 396293 & 256186 & \\
\hline \multicolumn{5}{|l|}{ Medications } \\
\hline EPO" & $580000(20000-4272000)$ & 556000 (96 000-856 000) & $520500(|44000-| 800000)$ & 0.444 \\
\hline Iron" & $38900(4900-480000)$ & $64000(8000-168000)$ & $20600(13800-84600)$ & 0.160 \\
\hline Blood transfusion" & 205500 (36 500-67। 250) & 277200 (55 800-697 000) & $217500(30000-690000)$ & 0.229 \\
\hline Hypertension drugs" & 167865 (42 000-698 614) & 202380 ( 13 560-593 400) & $129945(13800-356000)$ & 0.346 \\
\hline Heparin* & $82600(32400-526$ 296) & $37800(8$ 100-196 600) & $26400(7450-134$ 100) & $<0.00$ । \\
\hline Other medications* & 120800 (26 000-597 240) & 82900 (8 I00-238 680) & $24000(100-310840)$ & $<0.001$ \\
\hline Laboratory and radiology* & I52 800 (27 000-| 020800$)$ & $162450(19400-800400)$ & $27000(2$ 000-434 400) & $<0.00$ I \\
\hline Consultation fees ${ }^{*}$ & 14000 (10 200-84 000) & 7500 (6 000-84 000) & | 800 (| 200-14 400) & $<0.001$ \\
\hline Feeding ${ }^{*}$ & $80800(4800-352800)$ & $104000(5000-255000)$ & $61600(12800-336000)$ & $<0.001$ \\
\hline Transport & II 4000 (3 840-7|4 000) & I 19400 (3000-1 642200$)$ & I74 500 (23 200-| 704000$)$ & 0.163 \\
\hline Vascular access* & $172000(60000-575800)$ & 142500 (42 500-385 000) & $107500(60000-570000)$ & 0.850 \\
\hline Hospitalization $^{*}$ & | 399240 (30 400-6 80| 098) & 382950 (40 000-1 698070$)$ & 179400 (23 000-815 000) & 0.013 \\
\hline Vaccination* & $42000(42000-42000)$ & $16000(16000-16000)$ & 7000 (7 000-7 000) & 0.223 \\
\hline Patient's time* & $246528(0-|\quad| 66754)$ & $289542(0-605382)$ & $266058(0-874682)$ & 0.175 \\
\hline Total out-of-pocket costs & 3650505 & 2650080 & | 7304 | | & \\
\hline Total state/hospital costs & 5206509 & 5110748 & 4719831 & \\
\hline Total costs & 9103542 & 8050370 & 6716300 & \\
\hline
\end{tabular}

when the state subsidizes dialysis, the cost covered by patients is high and the majority cannot afford it. Morbidity and mortality are consequently high [32-4I].

In SSA, poverty is rampant and over $40 \%$ of the population is estimated to live on less than one dollar per day [42]. Given the constant increase in the number of patients requiring dialysis in Cameroon, and considering that haemodialysis is the only modality available, it is imperative to identify cost-effective strategies to meet the demand for renal services. There is a need for policymakers in low-income countries to look for ways to reduce the cost of dialysis. One major step could be that governments build infrastructure to produce dialysis supplies and generic medications locally, and remove the import duty charged on dialysis consumables. Renal transplantation, which is a more cost-effective treatment for ESRD, remains lack of qualified health personnel and appropriate infrastructure $[43,44]$. The most important factor is to reduce the number of patients developing ESRD. Identification and optimal treatment of CKD in high-risk populations, especially in resource-limited settings, remains the only costeffective and sustainable means of curbing the cost of managing ESRD. However, this approach is still in its infancy in most SSA countries and is not subsidized by the state in Cameroon [45-47].

Some limitations of this study include the fact that we did not incorporate the costs of staff overheads, infrastructure and utilities such as sanitation and laundry. Also, we based our calculations on actual expenditure, which may lead to an underestimation since certain items are self-funded and patients pay for what they can afford, not for what they need. Despite these limitations, this study provides the first estimates of the operational costs of haemodialysis 
in Cameroon, where this therapy has been available for more than two decades. The results will help healthcare planners to develop strategies to improve the care of these patients.

\section{CONCLUSIONS}

This multi-centre study demonstrated that the global cost of care of patients on haemodialysis in Cameroon is extremely high compared with the national gross domestic product per capita and that it is mainly due to the cost of dialysis consumables. Most patients are at a low socioeconomic level and, despite the state subsidy, out-ofpocket expenditure is extremely high and unaffordable by patients and their relatives in the long term. Haemodialysis is an economic burden on the country, and therefore strategies such as removing import duties on dialysis consumables and establishing kidney transplantation should be implemented. CKD screening and prevention programmes to reduce the number of persons in need of RRT are necessary and this remains the only cost-effective and sustainable approach, especially in developing countries.

\section{Acknowledgment}

We sincerely thank all the patients who participated in this study.

\section{Conflict of interest}

None to declare.

\section{REFERENCES}

I. Lysaght MJ. Maintenance dialysis population dynamics: current trends and long-term implications. J Am Soc Nephrol. 2002; I3(Suppl I):S37-40.

2. Liyanage T, Ninomiya T, Jha V, Neal B, Patrice HM, Okpechi I, et al. Worldwide access to treatment for end-stage kidney disease: a systematic review. Lancet. 2015; 385(9981):1975-1982.

3. Collins AJ, Foley RN, Chavers B, Gilbertson D, Herzog C, Johansen K, et al. United States Renal Data System 20 I I Annual Data Report. Am J Kidney Dis. 2012; 59(Suppl I):A7, el-420.

4. Jha V, Garcia-Garcia G, Iseki K, Li Z, Naicker S, Plattner B, et al. Chronic kidney disease: global dimension and perspectives. Lancet. 20 I 3; 382(9888):260-72.

5. Benain J-P, Faller B, Briat C, Jacquelinet C, Brami M, Aoustin M, et al. Coût de la prise en charge de la dialyse en France. Néphrologie Thérapeutique. 2007; 3(3):96-106.

6. De Vecchi AF, Dratwa M, Wiedemann ME. Healthcare systems and end-stage renal disease (ESRD) therapies-an international review: costs and reimbursement/funding of ESRD therapies. Nephrol Dial
7. Mushi L, Marschall P, Fleßa S. The cost of dialysis in low and middleincome countries: a systematic review. BMC Health.

$2015 ; 15(1)$.

8. Peeters P, Rublee D, Just PM, Joseph A. Analysis and interpretation of cost data in dialysis: review of Western European literature. Health Policy Amst Neth. 2000; 54(3):209-27.

9. Karopadi AN, Mason G, Rettore E, Ronco C. Cost of peritoneal dialysis and haemodialysis across the world. Nephrol Dial Transplant. 2013; 28(I0):2553-69.

10. UK Department of Health. The National Service Framework for Renal Services Part I: Dialysis and Transplantation. 2004. https:// www.kidney.org.uk/documentlibrary/pt I-toolkit4comm.pdf.

II. Alasia DD, Emem-Chioma P, Wokoma FS. A single-centre 7-year experience with end-stage renal disease care in Nigeria-a surrogate for the poor state of ESRD care in Nigeria and other sub-Saharan african countries: advocacy for a global fund for ESRD care program in sub-Saharan african countries. Int J Nephrol. 2012; Article ID 639653.

12. Bamgboye EL. Haemodialysis: management problems in developing countries, with Nigeria as a surrogate. Kidney Int Suppl. 2003; (83):S93-95.

13. Cameroon GDP and economic data. Global Finance Magazine. https://www.gfmag.com/global-data/country-data/cameroon-gdpcountry-report. Accessed 28 July 2016.

14. Kaze FF, Halle MP, Mopa HT, Ashuntantang G, Fouda H, Ngogang J, et al. Prevalence and risk factors of chronic kidney disease in urban adult Cameroonians according to three common estimators of the glomerular filtration rate: a cross-sectional study. BMC Nephrol. 2015; 16(1).

15. Kaze FF, Meto DT, Halle MP, Ngogang J, Kengne AP. Prevalence and determinants of chronic kidney disease in rural and urban Cameroonians: a cross-sectional study. BMC Nephrol. 2015; I6(I).

16. Kaze FF, Kengne AP, Choukem SP, Dzudie A, Halle M, Dehayem M, et al. Dialysis in Cameroon. Am J Kidney Dis. 2008; 5 I (6): I072-1074;

17. Arefzadeh A, Lessanpezeshki M, Seifi S. The cost of haemodialysis in Iran. Saudi J Kidney Dis Transplant. 2009; 20(2):307-3। I.

18. Collins AJ, Foley RN, Gilbertson DT, Chen S-C. United States Renal Data System public health surveillance of chronic kidney disease and end-stage renal disease. Kidney Int Suppl. 20I 5; 5( I):2-7.

19. Abu-Aisha H, Elamin S. Peritoneal dialysis in Africa. Perit Dial Int. 2010; 30(I):23-28.

20. Okafor C, Kankam C. Future options for the management of chronic kidney disease in Nigeria. Gend Med. 2012; 9(1):S86-93.

21. Al Saran K, Sabry A. The cost of haemodialysis in a large haemodialysis centre. Saudi J Kidney Dis Transplant. 2012; 23(I):78-82.

22. Mushi L, Krohn M, Flessa S. Cost of dialysis in Tanzania: evidence from the provider's perspective. Health Econ Rev. 20। 5; 5:28.

23. de Abreu MM, Walker DR, Sesso RC, Ferraz MB. A cost evaluation of peritoneal dialysis and haemodialysis in the treatment of end-stage renal disease in São Paulo, Brazil. Perit Dial Int. 2013; 33(3):304-315.

24. Prodjosudjadi W. Incidence, prevalence, treatment and cost of end-stage renal disease in Indonesia. Ethn Dis. 2006; 16(Suppl 2): 14 - 16. 
25. Li PK, Chow KM. The cost barrier to peritoneal dialysis in the developing world-an Asian perspective. Perit Dial Int. 200I; 2 I (Suppl 3):7-13.

26. Elsharif ME, Elsharif EG, Gadour WH. Costs of haemodialysis and kidney transplantation in Sudan: a single centre experience. Iran J Kidney Dis. 20 I0; 4(4):282-284.

27. Khanna $\cup$. The economics of dialysis in India. Indian J Nephrol. 2009; 19(1): I.

28. Ranasinghe P, Perera YS, Makarim MFM, Wijesinghe A, Wanigasuriya $K$. The costs in provision of haemodialysis in a developing country: a multi-centered study. BMC Nephrol. $2011 ; 12: 42$

29. Eriksson JK, Neovius M, Jacobson SH, Elinder C-G, Hylander B. Healthcare costs in chronic kidney disease and renal replacement therapy: a population-based cohort study in Sweden. BMJ Open. 2016; 6(10):e012062.

30. Lorenzo V, Perestelo L, Barroso M, Torres A, Nazco J. Economic evaluation of haemodialysis. Analysis of cost components based on patient-specific data. Nefrologia. 20 I0; 30(4):403-4I2.

31. Icks A, Haastert B, Gandjour A, Chernyak N, Rathmann W, Giani G, et al. Costs of dialysis-a regional population-based analysis. Nephrol Dial Transplant. 20 10; 25(5): I 647-1652.

32. Arogundade FA, Sanusi AA, Hassan MO, Akinsola A. The pattern, clinical characteristics and outcome of ESRD in lle-Ife, Nigeria: is there a change in trend? Afr Health Sci. 20 I I; I I (4):594-60 I.

33. Sumaili EK, Cohen EP, Zinga CV, Krzesinski J-M, Pakasa NM, Nseka NM. High prevalence of undiagnosed chronic kidney disease among at-risk population in Kinshasa, the Democratic Republic of Congo. BMC Nephrol. 2009; 10: 18.

34. Naicker S. End-stage renal disease in sub-Saharan and South Africa. Kidney Int. 2003; 63(Suppl 83):SI I9-122.

35. Bamgboye EL. Hemodialysis: management problems in developing countries, with Nigeria as a surrogate. Kidney Int. 2003; 63:S93-95.

36. Ashuntantang G, Osafo C, Olowu WA, Arogundade F, Niang A, Porter J, et al. Outcomes in adults and children with end-stage kidney disease requiring dialysis in sub-Saharan Africa: a systematic review. Lancet Glob Health. 2017; 5(4):e408-417.

37. Niang A, Cisse MM, Mahmoud SMOM, Lemrabott ATO, Ka EHF, Diouf B. Pilot experience in Senegal with peritoneal dialysis for end-stage renal disease. Perit Dial Int. 2014; 34(5):539-543.

38. Dreyer G, Dobbie H, Banks R, et al. Supporting Malawi's dialysis services with the international community. $\mathrm{Br}$ J Renal Med. 2012; 17:24-26.

39. Kaze FF, Ashuntantang G, Kengne AP, Hassan A, Halle MP, Muna W. Acute haemodialysis complications in end-stage renal disease patients: The burden and implications for the underresourced Sub-Saharan African health systems. Hemodial Int. 2016; | 6(4):526-531.

40. Bah AO, Nankeu N, Balde MC, Kaba ML, Bah BK-H, Rostaing L. Quality of life of patients with end-stage renal disease in Guinea. Saudi J Kidney Dis Transplant. 20|4; 25(6): |346-I35 I.

41. Okafor UH, Ekwem I, Wokoma FS. Challenges of kidney care in a resource poor nation: A study of private kidney care centre in Nigeria. Niger Med J. 2012; 53( I):47-50.

42. Human Development Report 2003. United Nations. http://hdr. undp.org/en/content/human-development-report-2003.
43. Tshamba HM, Van Caillie D, Nawej FN, Kapend FM, Kaj FM, Yav GD, et al. Risk of death and the economic accessibility at the dialysis therapy for the renal insufficient patients in Lubumbashi city, Democratic Republic of Congo. Pan Afr Med J. 2014; 19:61.

44. Nayak Karopadi A, Mason G, Rettore E, Ronco C. The role of economies of scale in the cost of dialysis across the world: a macroeconomic perspective. Nephrol Dial Transplant. $2014 ; 29(4): 885-892$.

45. Wolfe RA, Ashby VB, Milford EL, Ojo AO, Ettenger RE, Agodoa LY, et al. Comparison of mortality in all patients on dialysis, patients on dialysis awaiting transplantation, and recipients of a first cadaveric transplant. N Engl J Med. 1999; 34I (23): I725-I730.

46. Laupacis A, Keown P, Pus N, Krueger H, Ferguson B, Wong C, et al. A study of the quality of life and cost-utility of renal transplantation. Kidney Int. 1996; 50( I):235-242.

47. Klarenbach S, Manns B. Economic evaluation of dialysis therapies. Semin Nephrol. 2009; 29(5):524-532. 